\title{
Flow pattern and anti-silt measures of straight-edge forebay in large pump stations
}

\author{
Cundong $\mathrm{Xu}^{1,2,3}$, Rongrong Wang ${ }^{1 *}$, Hui Liu ${ }^{4}$, Rui Zhang ${ }^{1}$, Mingyan Wang ${ }^{1}$, Yan Wang ${ }^{1}$ \\ ${ }^{1}$ School of Water Conservancy, North China University of Water Resources and Electric Power, Zhengzhou 450046, China \\ ${ }^{2}$ Collaborative Innovation Center of Water Resources Efficiency and Protection Engineering, Zhengzhou 450046, China \\ ${ }^{3}$ Henan Provincial Hydraulic Structure Safety Engineering Research Center, Zhengzhou 450046, China \\ ${ }^{4}$ Henan Tianchi Pumped Storage Co., LTD., Nanyang 473000, China
}

Corresponding Author Email: wrrong369@163.com

https://doi.org/10.18280/ijht.360346

Received: 10 February 2018

Accepted: 18 April 2018

\section{Keywords:}

forebay of pump station, silt accumulation, numerical simulation, trapezoid diversion pier, $45^{\circ}$ pressure plate

\begin{abstract}
Forebay sedimentation is a common problem in large pump stations because the water is taken in from heavily silt-carrying rivers. Targeting the \#3 Pump Station of West Trunk Line (Phase I), Gansu Jingtaichuan Irrigation District, the author learned about the current situation of forebay sedimentation through site investigation, and constructed a 3D structural model of prototype forebay based on ICEM-CFD. Furthermore, the flow pattern of the straight-edge front inflow (SEIF) forebay was simulated based on FLUENT. Then, two anti-silt measures, i.e. diversion pier and pressure plate, were put forward to improve the flow pattern of the forebay. The results show that the simulation results on forebay flow pattern agree well with the data acquired through site investigation; the trapezoid diversion pier reduced the range of the main reflux zone to some extent by distributing the forebay flow, failing to obviously improve the distribution of the flow field; the $45^{\circ}$ pressure plate exhibited obvious optimization effect, reducing the range and intensity of reflux zone on both sides of the forebay.
\end{abstract}

\section{INTRODUCTION}

The north-western China is an arid region short in water but rich in land, light and heat resources. To solve the imbalance between water and land, China has built large cascade irrigation districts in the Yellow River Basin, turning vast stretches of barren land into oases. This move not only improves the production and living conditions in these districts, but also optimizes the local microclimates and ecological conditions. However, many of the irigation districts in the Yellow River Basin face severe sedimentation in the forebays of pump stations, owing to the high silt content of the water source [1] and the bad flow patterns (e.g. diversion and separation). In return, the sedimentation in the forebay intensifies the worsening of the flow pattern. To reduce forebay sedimentation, improve pumping efficiency and cut pumping cost, it is of great importance to identify the flow patterns in the forebay and roll out improvement measures. Of course, the water flow in the forebay is compelx and constantly changing, due to the great water depth during the operation of the pump station [2].

In recent years, fruitfull results have been achieved at home and abroad through the simulation of forebay flow pattern using 3D turbulent model. Through simulation, Fletcher et al. [3] modified the diversion design of pump orifice, and verified that the modification improves the flow features of the forebay and control the water intake well near the pressure pump. Shafai-Bajestan et al. [4] modified the Froude measurement model to evaluate the effect of structural changes near the water inlet of the pump station on sedimentation. Constantinescu and Patel [5] simulated the forebay whirlpool of pump station by standard k- $\varepsilon$ model, and verified the similarity between the simulated whirlpool and the result of the model test, revealing that the whirlpool position and intensity are affected by the selection of mathematical turbulent model and boundary conditions. Liu et al. [6] proposed several forebay modification plans in light of the diversion features of the first-stage pump station in Tianshan Irrigation District, and proved through 3D numerical simulation that the combination of pressure plate and noncontinuous sill/flip bucket is the best flow pattern improvement plan for forebay and inlet tank. Han et al. [7] established the 3D numerical simulation model of water pump forebay and flow channel based on Re-Normalization Group (RNG) turbulent model, and applied it to simulate the hydraulic features of steady and transient flows. Nakato [8] built a 1:24 indoor test model for the forebay of the pump station in Chicot Lake, and compared the model test results with field survey data, concluding that the distribution of silt deposition is closely related to the average water depth, average flow velocity and water flow pattern. Despite the above studies, there is little report on the simulation technology for forebay flow pattern or anti-silt measures for straight-edge front inflow (SEFI) forebay in large pump stations. The front inflow (FI) forebay is one of the two main types of forebays in pump station, alongside with the lateral inflow forebay. The previous studies have shown that the FI forebay is more prone to sedimentation than lateral inflow forebay.

Targeting the SEFI forebay in \#3 pump station of the West Trunk Line (Phase I) in Gansu Jingtaichuan Irrigation District (hereinafter referred to as the "irrigation district"), this paper numerically simulates the typical flow patterns in the forebay, modifies the forebay flow pattern using trapezoid diversion pier and pressure plate, and determines the optimal parameters for the two rectification measures. 


\section{SITE INVESTIGATION}

\subsection{Overview of the study area}

Located in the arid area in north-western China, the study area is a large (Class II) cascade irrigation district in the Yellow River Basin. With 43 pump stations, the irrigation district boasts a total installed capacity of $259,700 \mathrm{~kW}$ and a designed water flow of $28.6 \mathrm{~m}^{3} / \mathrm{s}$. Here, the forebay in \#3 pump station of the West Trunk Line (Phase I). There are six units in the pump station. For $\# 1, \# 2$ and $\# 3$ units, the flow is $0.85 \mathrm{~m}^{3} / \mathrm{s}$ and the suction pipe diameter is $800 \mathrm{~mm}$; For $\# 4$ unit, the flow is $0.28 \mathrm{~m}^{3} / \mathrm{s}$ and the suction pipe diameter is $500 \mathrm{~mm}$; For $\# 5$ unit, the flow is $1.6 \mathrm{~m}^{3} / \mathrm{s}$ and the suction pipe diameter is $1,000 \mathrm{~mm}$. Besides, the suction pipes are installed at the elevation of $1,656.40 \mathrm{~m}$, the forebay water level is designed as $1,658.67 \mathrm{~m}$, and the diffusion angle of the forebay is $36^{\circ}$.

After years of operation, the high silt content of the diversion water source and the irrational design of pump station caused the poor flow pattern in the FI forebay, leading to serious silt deposition. This situation affects the normal operation of the pump station and restricts the full exertion of project benefits [1]. For the simulation accuracy, the calculation area in our research covers a $10 \mathrm{~m}$-long diversion channel, a gradient section, a lock chamber section, a horizontal section, a slope section and a suction pipe. Together, these components form a relatively complete flow field [9]. The structure of the SEFI forebay is illustrated in Figure 1 below.

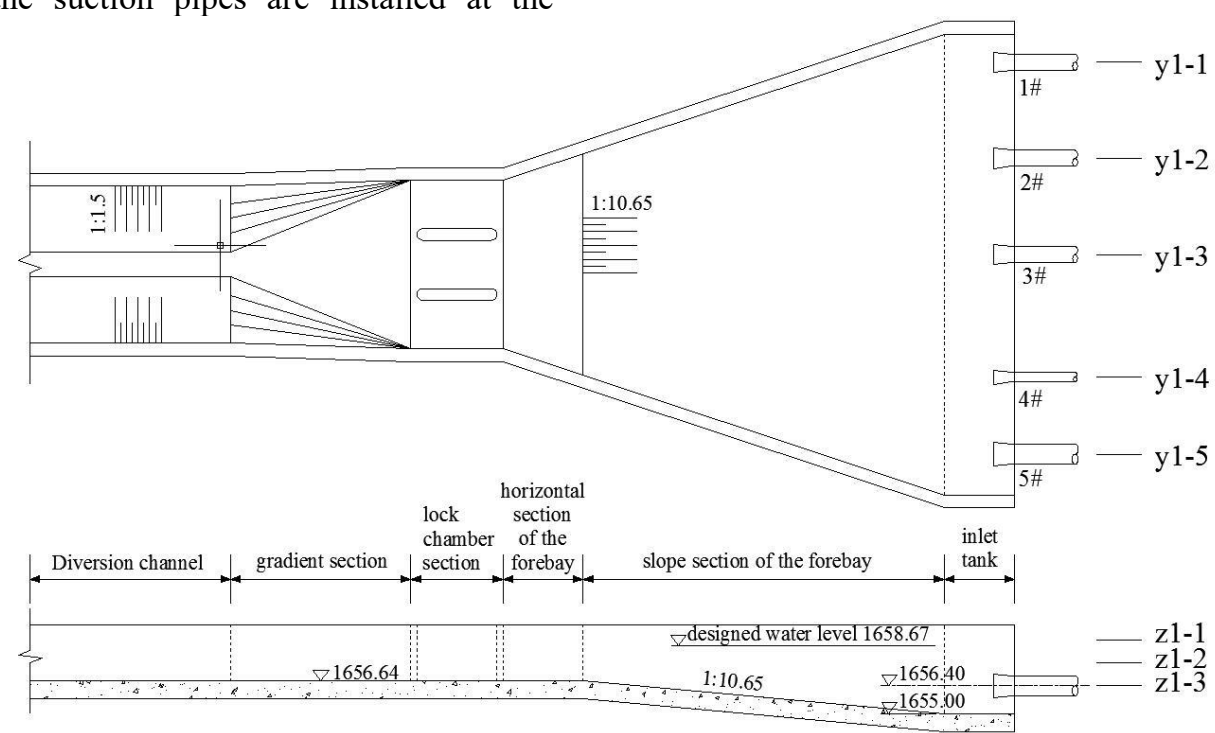

Figure 1. Structure of SEFI forebay

\subsection{Sedimentation status}

The water in the SEFI forebay of \#3 pump station flows along the water intake direction of the pump, either coinciding with or parallel to the centreline of the diversion channel. Site investigation shows that the forebays in most pump stations are suffering from varied degrees of sedimentation. In severe cases, the pump is unable to intake water normally from $1 / 3 \sim 1 / 2$ of the forebay and even the inlet tank is clogged by silt. The sedimentation mainly occurs at the bottom corners near the two sidewalls across the forebay centreline, and rarely near the mainstream at the centre. Figures 2 and 3 show the investigation results on forebay sedimentation.

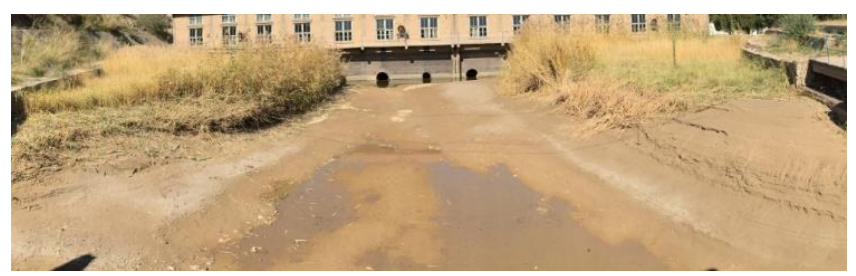

Figure 2. SEFI forebay sedimentation

As shown in Figures 2 and 3, the sedimentation in the forebay is roughly axisymmetric, with a $2.6 \mathrm{~m}$-thick top layer. Almost the entire forebay bottom is covered by gentle sloping sedimentation. A new water channel cuts through the sedimentation and develops into a bell-shape at the tail. Some silts settle in the inlet tank at the feet of both sides, which hinders the water intake by the pumps from these two sides.

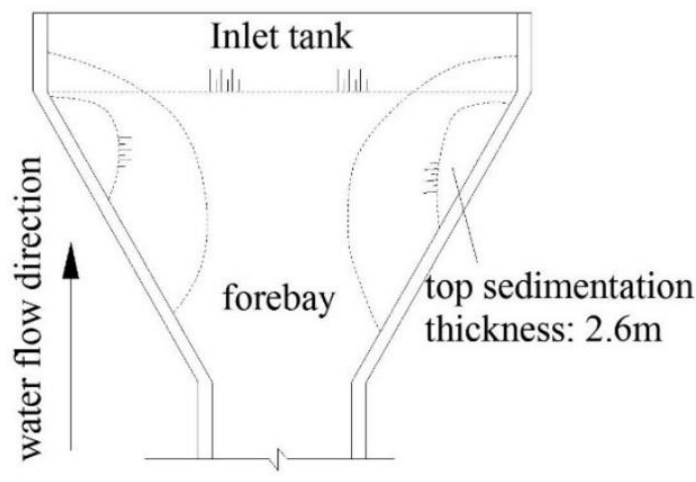

Figure 3. Sedimentation degrees of SEFI forebays

\subsection{Silt content and particle size in the water of the irrigation district}

High silt content is the leading cause of forebay sedimentation of pump stations in the irrigation district. The water and silt samples were taken from a typical forebay, and subjected to an indoor analysis. It is learned that the annual average silt content was about $30.0 \mathrm{~kg} / \mathrm{m}^{3}$, and the maximum silt content was about $382 \mathrm{~kg} / \mathrm{m}^{3}$. Table 1 and Figure 4 present the data and the curve of silt particle size, respectively. 
Table 1. Silt particle size in water of the irrigation district

\begin{tabular}{|c|c|c|c|c|c|c|}
\hline \multicolumn{7}{|c|}{ Particle gradation } \\
\hline \multirow{2}{*}{$\begin{array}{l}\text { Sieve size } \\
\quad(\mathrm{mm})\end{array}$} & \multicolumn{3}{|c|}{$\begin{array}{c}\text { Cumulative screen residue in standard } \\
\text { particle gradation range }(\%)\end{array}$} & \multirow{2}{*}{$\begin{array}{l}\text { Weight of screen } \\
\text { residue }(\mathrm{g})\end{array}$} & \multirow{2}{*}{$\begin{array}{l}\text { Partial screen } \\
\text { residue }(\%)\end{array}$} & \multirow{2}{*}{$\begin{array}{l}\text { Actual cumulative } \\
\text { screen residue }(\%)\end{array}$} \\
\hline & I zone & II zone & III zone & & & \\
\hline 9.5 & 0 & 0 & 0 & / & I & / \\
\hline 4.75 & $10-0$ & $10-0$ & $10-0$ & I & I & I \\
\hline 2.36 & $35-5$ & $25-0$ & $15-0$ & I & l & / \\
\hline 1.18 & $65-35$ & $50-10$ & $25-0$ & 0 & 0 & 0 \\
\hline 0.6 & $85-71$ & $70-41$ & $40-16$ & 0.3 & 0.06 & 0.06 \\
\hline 0.3 & $95-80$ & $92-70$ & $85-55$ & 0.2 & 0.04 & 0.1 \\
\hline 0.15 & $100-90$ & $100-90$ & $100-90$ & 1.7 & 0.34 & 0.44 \\
\hline 0.075 & l & I & l & 35.8 & 7.16 & 7.6 \\
\hline Sieve bottom & & & & 461.7 & 92.3 & 99.9 \\
\hline
\end{tabular}

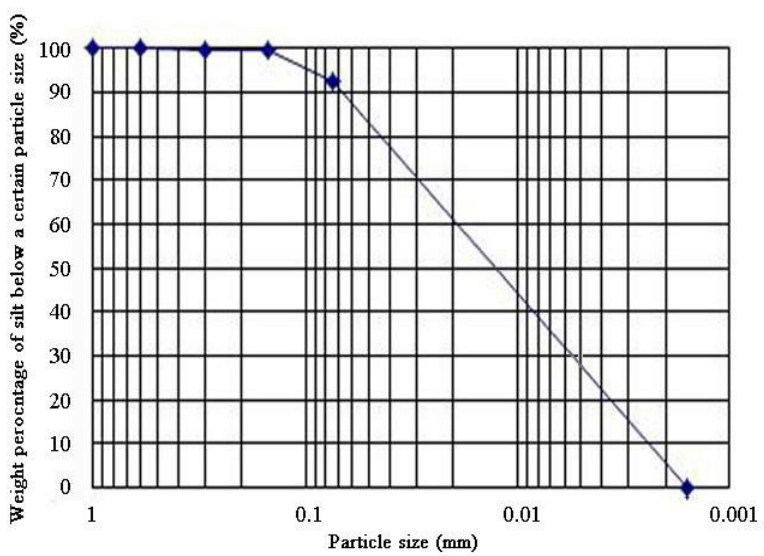

Figure 4. Curve of silt particle size in water of the irrigation district

According to the above results, $92.3 \%$ of the silts in the forebay of pump station in the irrigation district belong to extremely fine sandy soil with smaller-than- $0.075 \mathrm{~mm}$ of particle size. The silt-carrying water is a two-phase turbulent flow. The individual and collective properties of silt particles are deeply diversified due to the difference of the silts in in the size, shape, mineral composition and other factors, as well as the variation in gradation, porosity, permeability and diffusion rate of the silt.

The movement of the silt-carrying water is the result of the interaction between silt and two-phase water flow, the mutual influence between silts, and the impact of boundaries on water and silt. The high silt content in the water flow brings lots of negative consequences, such as serious sedimentation in the forebay, poor conditions of pump inlet, corrosion of flow passage components (e.g. impeller, pump casing and valve), short service life of such components, high maintenance and repair costs, and lower operation efficiency of the pump station. To ensure the normal operation of the pump station, it is imperative to reduce the silt content in the water flow.

\section{NUMERICAL SIMULATION}

\subsection{Algorithm theory}

FLUENT is an immensely popular CFD software capable of simulating complex flows, ranging from the incompressible level to highly compressible level [10]. The most important component of FLUENT is the turbulent model, while the most suitable grid software for FLUENT is ICEM-CFD, a highly intelligent CFD/CAE pre-processing software [11]. It can achieve fast and accurate grid meshing and adjustment [12].

In this research, the forebay flow is in an incompressible turbulent motion, and the mainstream fluid of the pump station belongs to the high Reynolds number turbulent state. Given the large size of the forebay and the apparent variation of flow regime, there are often significant reflux and wall-detached flow.

Considering the above, the standard $\mathrm{k}-\varepsilon$ model was adopted to satisfy the accuracy requirements, time constraints and computer capacity. As the most basic form of the k- $\varepsilon$ twoequation turbulent model of the vortex model, the standard k$\varepsilon$ model integrates the turbulent kinetic energy $\mathrm{k}$ equation and the dissipation rate $\varepsilon$ equation. The model boasts strong versatility when applied to fully developed turbulence with high Reynolds number [13]. In this simple and accurate model, the default fluid inertia force is greater than the viscous force, the fluid movement is unstable, and the irregular turbulent flow field is easily formed [14].

\subsection{Control equations}

Fluid movement follows the laws of conservation of mass, momentum and energy [15]. The forebay flow of the pump station is a complicated 3D turbulent movement. Here, the energy equation is negligible because the forebay flow is an incompressible fluid of constant density. Thus, it is necessary to take account of the heat-exchange capacity of the fluid [16]. In light of these, the control equations of the water flow in the forebay can be expressed as follows [17]:

(1) The continuity equation derived from the law of conservation of mass:

$$
\frac{\partial u_{i}}{\partial x_{i}}=0
$$

(2) Momentum conservation equation:

$$
\frac{\partial\left(\rho u_{i}\right)}{\partial t}+\frac{\partial\left(\rho u_{i} u_{j}\right)}{\partial x_{j}}=-\frac{\partial p}{\partial x_{i}}+\frac{\partial}{\partial x_{j}}\left[\mu_{e f f}\left(\frac{\partial u_{i}}{\partial x_{j}}+\frac{\partial u_{j}}{\partial x_{i}}\right)\right]+\rho g_{i}
$$

where $\mu_{i}$ and $\mu_{j}$ are the velocity vectors of the $i$-th and $j$-th directions, respectively; $x_{i}$ and $x_{j}$ are the axes of coordinates; $\rho$ is the fluid density; $t$ is the time; $p$ is the static pressure containing turbulent kinetic energy; $\mu_{\text {eff }}$ is the effective viscosity coefficient of fluid movement; $\rho g_{i}$ is the gravity component in the $i$-th direction. 


\subsection{Standard k- $\varepsilon$ model}

Based on the dissipation rate of turbulent kinetic energy, the standard k- $\varepsilon$ model is a semi-empirical formula for fully developed turbulence with high Reynolds number [18]. The stability and accuracy of the model have been repeatedly validated [19-20]. In the pump station, the forebay flow pattern is a high Reynolds number turbulence, which is suitable for the standard k- $\varepsilon$ model. The equations for the turbulent kinetic energy and its dissipation rate can be expressed as [17]:

$$
\begin{aligned}
& \frac{\partial}{\partial x_{j}}\left[\rho u_{j} k-\left(\mu+\frac{\mu_{t}}{\sigma_{k}}\right) \frac{\partial k}{\partial x_{j}}\right]=\rho\left(P_{k}-\varepsilon\right) \\
& \frac{\partial}{\partial x_{j}}\left[\rho u_{j} \varepsilon-\left(\mu+\frac{\mu_{t}}{\sigma_{\varepsilon}}\right) \frac{\partial \varepsilon}{\partial x_{j}}\right]=\rho \frac{\varepsilon}{k}\left(C_{1 \varepsilon} P_{k}-C_{2 \varepsilon} \varepsilon\right)
\end{aligned}
$$

where $\mu$ is the laminar viscosity coefficient; $\mu_{t}$ is the turbulent viscosity coefficient; $\mu_{e f f}=\mu+\mu_{t}, \mu_{t}=\rho C_{\mu} \frac{k^{2}}{\varepsilon} ; P_{k}$ is the turbulence product items; $C_{l \varepsilon}, C_{2 \varepsilon}, C_{\mu}, \sigma_{k}$ and $\sigma_{\varepsilon}$ are the empirical constants, whose values are $1.44,1.92,0.09,1.0$ and 1.3 , respectively; Other symbols have the same meaning as before.

\subsection{Boundary conditions}

(1) The velocity inlet was adopted as the boundary condition for the forebay inlet section, for the mean velocity can be determined according to the design flow of the pump station and the size of the forebay station.

(2) Since the outlet velocity and pressure are unknown, it is assumed that the outlet boundary has no effect on the upstream water movement and the flow is fully developed. Therefore, the outlet boundary condition was selected as the outflow boundary condition [22].

(3) In the near-wall area, the fluid motion changes violently, especially in the viscous bottom layer. Dominated by the viscous force, the fluid movement is basically a laminar flow that cannot be simulated by the k- $\varepsilon$ two-equation turbulent model. Therefore, the wall function method was employed to tackle the solid wall boundary.

(4) The free surface of the forebay is not subjected to significant external impacts or floating changes. Considering the requirements on meshing and calculating time, the free surface was simulated by the rigid-lid hypothesis method, that is, the free surface condition was set as symmetric in FLUENT [23-24].

\subsection{Meshing and flow field discretization}

The efficiency and accuracy of numerical simulation of flow problems hinge on the quality of grid generation and the meshing algorithm [25]. Considering the complex boundary conditions of the forebay and the presence of suction pipe and anti-silt facilities, the author conducted unstructured meshing of the model and increased the density of grids in local areas [26-27]. Besides, the number of grids was adjusted for checking calculation. The result error fell within 5\%, indicating that the model passed the grid independent test. In total, there were $1,074,457$ grids in this model. The calculation area was discretized by the FLUENT using the finite volume method [28-29]. The implicit solution of the second-order upwind plan was used to ensure the computing accuracy and the flow field coupling was performed by the semi-implicit method for pressure linked equations-consistent (SIMPLEC) algorithm [30].

\subsection{Numerical simulation and analysis}

Under the above conditions, all 5 units ran simultaneously at the design flow, putting the total design flow at $4.43 \mathrm{~m}^{3} / \mathrm{s}$. According to the actual size of the forebay, a 3D geometric model was created and meshed by ICEM-CFD (Figures 5 and 6).

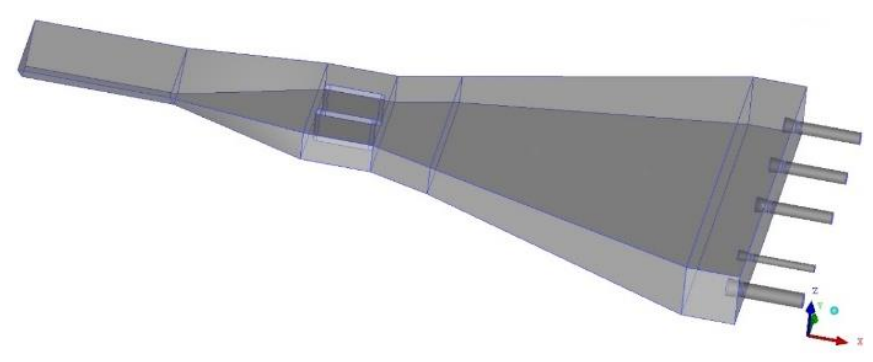

Figure 5. 3D geometric model of SEFI forebay

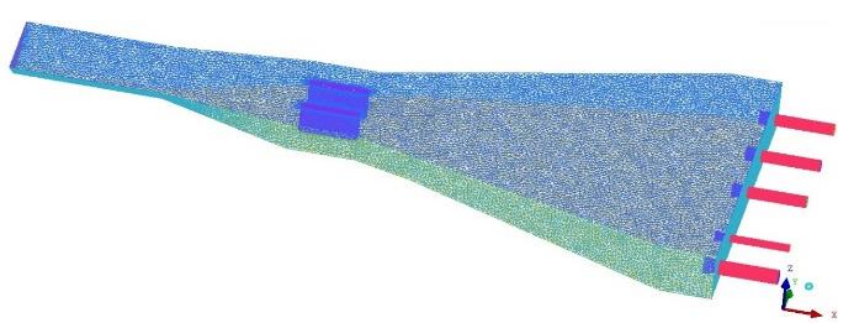

Figure 6. Meshing of the calculation area of the SEFI forebay

The grid files generated by ICEM-CFD were imported into FLUENT for subsequent analysis. The parameters of the physical model inputted for simulation are listed in Table 2 below.

The simulation calculation is precise to four decimal digits. During the calculation, the convergence was slow, the errors of the inlet and outlet flows were very small, and the residual parameters were basically stable. All these bear witness to the good convergence and computing accuracy of the simulation [31]. The positions of the target sections are given in Figure 1, and the parameters of each section are displayed in Table 3. In addition, Figures 7 10 present the flow field distribution of each section (unit: $\mathrm{m} / \mathrm{s}$ ).

The simulation results show that the mainstream occurred in the middle of the forebay, with asymmetrical vertical axis whirlpool on both sides. Along the direction of water flow, the right side of the forebay was more turbulent than the left side. Meanwhile, the mainstream diffusion slowed down and the mainstream channel shrank gradually due to the due to the squeezing effect of the whirlpool. 
Table 2. Parameters of physical model

\begin{tabular}{cccccc}
\hline $\begin{array}{c}\text { Calculation } \\
\text { parameters }\end{array}$ & $\begin{array}{c}\text { Inlet velocity } \\
\mathrm{v}(\mathrm{m} / \mathrm{s})\end{array}$ & $\begin{array}{c}\text { Acceleration of } \\
\text { gravity g }\left(\mathrm{m} / \mathrm{s}^{2}\right)\end{array}$ & $\begin{array}{c}\text { Hydrodynamic } \\
\text { viscosity u }(\mathrm{kg} / \mathrm{m} \cdot \mathrm{s})\end{array}$ & $\begin{array}{c}\text { Turbulent kinetic } \\
\text { energy k }\left(\mathrm{m}^{2} / \mathrm{s}^{2}\right)\end{array}$ & $\begin{array}{c}\text { Turbulent kinetic energy } \\
\text { dissipation rate } \varepsilon\left(\mathrm{m}^{2} / \mathrm{s}^{2}\right)\end{array}$ \\
\hline Value & 0.6018 & 9.8 & 0.001003 & $3.7815 \exp (-4)$ & $4.39192 \exp (-6)$ \\
\hline
\end{tabular}

Table 3. Parameters of the target sections

\begin{tabular}{cccc}
\hline Observation sections & Section parameters $(\mathrm{m})$ & Observation sections & Section parameters $(\mathrm{m})$ \\
\hline $\mathrm{y} 1-1$ & $\mathrm{y}=10.1$ & $\mathrm{z} 1-1$ & $\mathrm{z}=-0.79$ \\
$\mathrm{y} 1-2$ & $\mathrm{y}=5.3$ & $\mathrm{z} 1-2$ & $\mathrm{z}=-1.915$ \\
$\mathrm{y} 1-3$ & $\mathrm{y}=0.5$ & $\mathrm{z} 1-3$ & $\mathrm{z}=-3.05$ \\
$\mathrm{y} 1-4$ & $\mathrm{y}=-5.62$ & & \\
$\mathrm{y} 1-5$ & $\mathrm{y}=-9.47$ & & \\
\hline
\end{tabular}

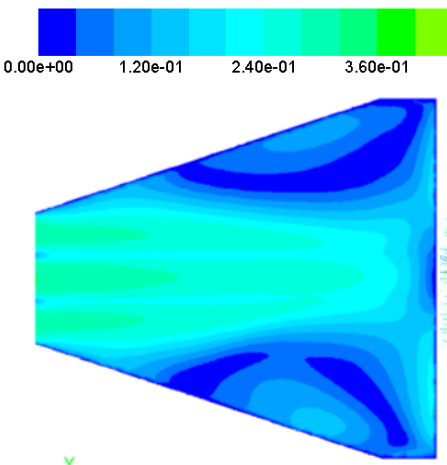

(a) Nephogram

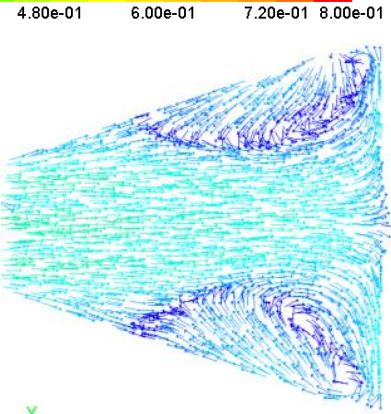

(b) Vectorgraph

Figure 7. Velocity distribution of the surface section z1-1

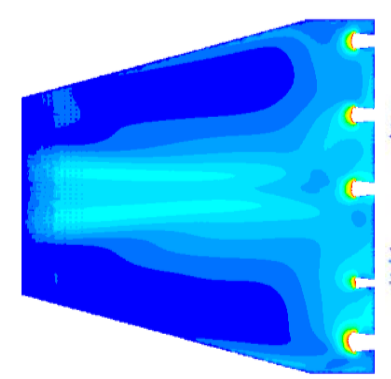

(a) Nephogram

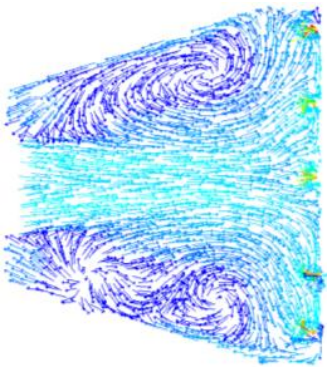

(b) Vectorgraph

Figure 9. Velocity distribution of the lower section z1-3

As shown in Figure 7, when the water flew to the surface layer of the forebay and the inlet tank, the mainstream channel began to shrink in the middle of the forebay, the water flow diffused to both ends of the tank under the action of the suction pipe and the back wall, and the flow velocity of the water on both sides of the back part of the forebay was reduced, forming a large reflux whirlpool.

As shown in Figure 8, compared with the surface water flow, the mainstream channel in the middle layer of the forebay flow was narrow, the reflux zone expanded to the vicinity of the inlet, the reflux intensity was high, and the reflux centre offset to the mainstream and squeezed the mainstream. In addition, the flow velocity of the middle layer was smaller than that of the surface layer.

As shown in Figure 9, under the action of the slope section, the lower stream spread toward the bottom of the forebay. The slow diffusion and low flow pressure suppressed the flow velocity, creating the conditions for the formation of reflux whirlpool. As the range of the reflux zone continued to expend, the mainstream was further squeezed, and restricted to the

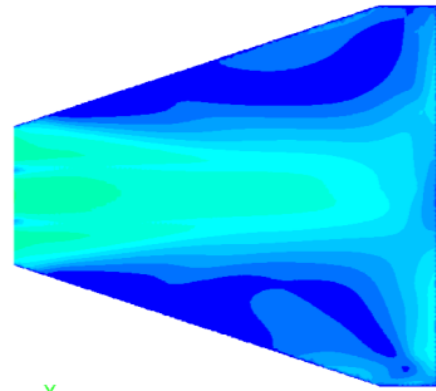

(a) Nephogram

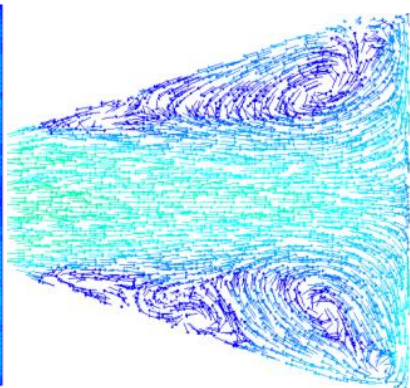

(b) Vectorgraph
Figure 8. Velocity distribution of the middle section z1-2

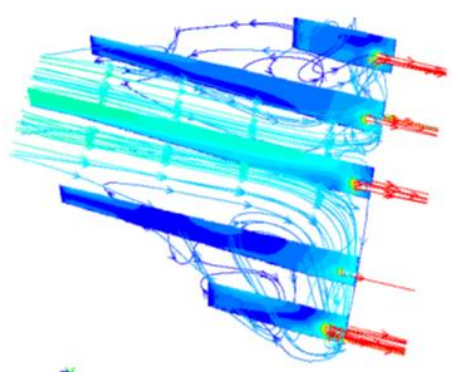

Figure 10. Velocity distribution cloud maps for sections y1-1 y1-5 and the streamlines in the forebay

middle of the forebay.

Figure 10 provides both the velocity distribution cloud maps and forebay streamline of longitudinal target sections of the pump station. As shown in the cloud maps, the surface layer had the greatest flow velocity, followed by the middle layer and then the lower layer. Meanwhile, the flow velocity decreased from the middle to both sides. Once the water flowed to the inlet tank, the flow velocity started to increase under the action of the suction pipe. According to the forebay streamlines, the mainstream and reflux zone of the forebay were separated obviously. The \#2, \#3, \#4 units near the mainstream enjoyed good water inlet conditions while the \#1 and \#5 units near the reflux zone had poor water inlet conditions.

It can be seen from the numerical simulation that sedimentation mainly occurred in the reflux zone with low flow velocity. Under the low flow velocity of the reflux zone, the silt transport capacity of the water flow was reduced due to the positive correlation between silt transport rate and the flow velocity. When the velocity fell below the minimum silt- 
carrying velocity, the silt in the water settled and deposited in the reflux zone. This conclusion agrees well with the result of site investigation, which verifies the reliability of the numerical simulation of the forebay flow pattern in the pump station.

\section{ANTI-SILT SIMULATION}

According to the Design Code for Pump Station (GB502652010) and the actual operation of the SEFI forebay (The Ministry of Water Resources of the People's Republic of China, 2011), two modification plans, i.e. the addition of diversion pier and the application pressure plate, were selected to improve the anti-silt effect.

\subsection{Plan one}

The trapezoid diversion pier in the forebay facilitates the adjustment of flow direction and distribution, such that the water could flow smoothly with an even volume distribution. In this way, it is possible to prevent the reflux, whirlpool and other undesirable hydraulic phenomena, and improve the flow field of forebay.

Located in the slope section, the trapezoid diversion pier adopts the symmetrical arrangement. Figure 11 describes the layout of the pier, including the position parameters (L1, L2, $\beta$ ) and dimension parameters (L3) [32]. The hydraulic features of the pier depend heavily on its position, angle and size. Therefore, the rationality of the parameters of the pier directly bears on the effect of the plan. Here, the pier length is set to $1,000 \mathrm{~cm}$ and the values of parameters $\mathrm{L} 1, \mathrm{~L} 2, \beta$ are set as in Table 4 . Besides, a total of 27 kinds of parameter combinations were designed, the geometric model was established and the grids were meshed according to the parameter combinations. The number of grid units ranged between 1.146 million and 1.513 million. The simulation results of some parameter combinations are shown in Figures 12 and 13 (unit: $\mathrm{m} / \mathrm{s}$ ).

Through the numerical simulation results, it is found that the trapezoid diversion pier could bypass the water flow of forebay, guide part of the mainstream to the sides and reduce the reflux zone on both sides of the forebay. However, the horizontal and vertical diffusions of forebay flow were improved poorly: the original mainstream was split into three parts, leading to uneven distribution of the flow field; the lack of silt-carrying capacity of the water flow caused the sedimentation of silt in the forebay.

The modification effect of diversion pier varied with the parameter values. When $\mathrm{L} 1$ was $800 \mathrm{~cm}$, the diversion pier was too far away from the forebay inlet, failing to control the mainstream. As shown in Figures 12(a) (c), the distortion of the mainstream channel outweighed the slight reduction in the range of the reflux zone at the end of the forebay, resulting in a wide reflux zone and a complex flow pattern. As shown in Figures $12(\mathrm{~d}) \sim(\mathrm{e})$, when $\beta$ was $15^{\circ}$, the diversion pier could guide most water flow to the end of the forebay, and significantly squeeze and reduce the reflux zone on both sides. However, it was extremely easy for a large whirlpool to appear on the back surface of the pier, and the mainstream within the pier was severely compressed, which affected the horizontal diffusions of mainstream.

Through comparison, 3 out of the 27 parameter combinations (Figures 12(f) (h)) brought relatively good improvement effects, including balanced distribution of water flow and flow field after the addition of the pier, the small reflux zone on both sides, and the weak whirlpool on the back. As shown in Figure 13, the water intake condition of each pump and the velocity vector distribution at middle layer were better than the other cases when $\mathrm{L} 1=600 \mathrm{~cm}, \mathrm{~L} 2=400 \mathrm{~cm}$ and $\beta=10^{\circ}$. Specifically, this combination enjoyed the best flow pattern in the forebay, the smallest reflux zone, the weakest pier back whirlpool and best water inlet conditions.

To sum up, the best parameter combination for improving the forebay flow pattern is: $\mathrm{L} 1=600 \mathrm{~cm}, \mathrm{~L} 2=400 \mathrm{~cm}, \mathrm{~L} 3=$ $1000 \mathrm{~cm}$ and $\beta=10^{\circ}$.

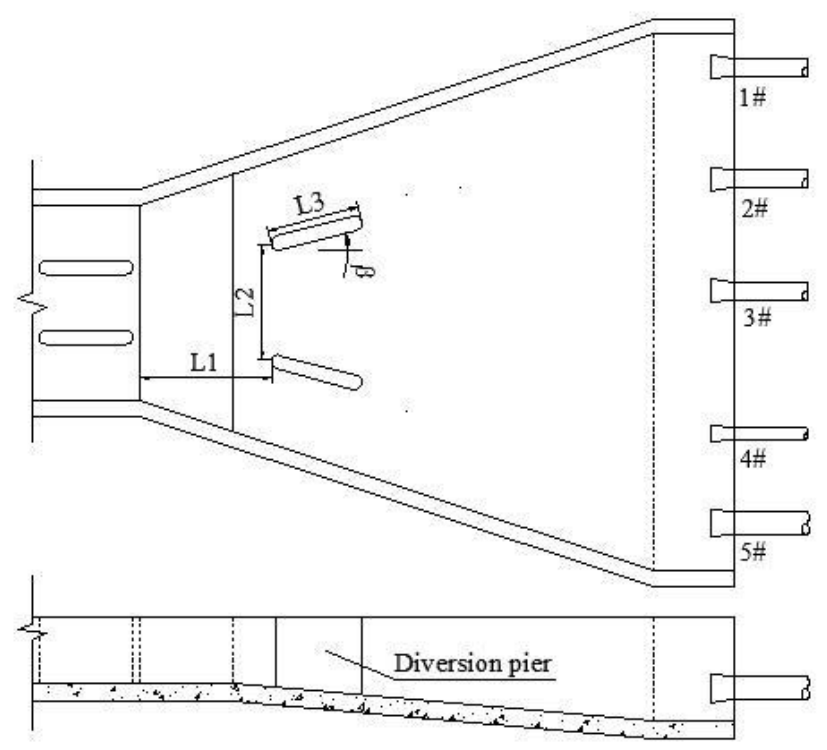

Figure 11. Layout of diversion pier in SEFI forebay

Table 4. Parameters of diversion pier

\begin{tabular}{cccc|cccc|cccc}
\hline NO. & L1 $(\mathrm{cm})$ & L2 $(\mathrm{cm})$ & $\beta$ & NO. & L1 $(\mathrm{cm})$ & L2 $(\mathrm{cm})$ & $\beta$ & NO. & L1 $(\mathrm{cm})$ & L2 $(\mathrm{cm})$ & $\beta$ \\
\hline 1 & 500 & 300 & $10^{\circ}$ & 10 & 600 & 300 & $10^{\circ}$ & 19 & 800 & 300 & $10^{\circ}$ \\
2 & 500 & 300 & $12^{\circ}$ & 11 & 600 & 300 & $12^{\circ}$ & 20 & 800 & 300 & $12^{\circ}$ \\
3 & 500 & 300 & $15^{\circ}$ & 12 & 600 & 300 & $15^{\circ}$ & 21 & 800 & 300 & $15^{\circ}$ \\
4 & 500 & 400 & $10^{\circ}$ & 13 & 600 & 400 & $10^{\circ}$ & 22 & 800 & 400 & $10^{\circ}$ \\
5 & 500 & 400 & $12^{\circ}$ & 14 & 600 & 400 & $12^{\circ}$ & 23 & 800 & 400 & $12^{\circ}$ \\
6 & 500 & 400 & $15^{\circ}$ & 15 & 600 & 400 & $15^{\circ}$ & 24 & 800 & 400 & $15^{\circ}$ \\
7 & 500 & 500 & $10^{\circ}$ & 16 & 600 & 500 & $10^{\circ}$ & 25 & 800 & 500 & $10^{\circ}$ \\
8 & 500 & 500 & $12^{\circ}$ & 17 & 600 & 500 & $12^{\circ}$ & 26 & 800 & 500 & $12^{\circ}$ \\
9 & 500 & 500 & $15^{\circ}$ & 18 & 600 & 500 & $15^{\circ}$ & 27 & 800 & 500 & $15^{\circ}$ \\
\hline
\end{tabular}




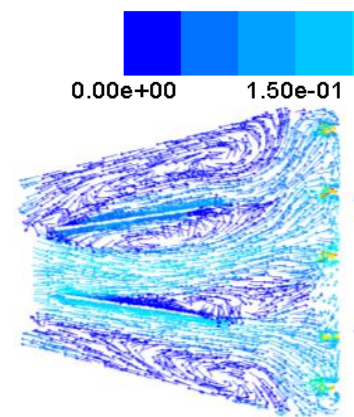

(a) $80050010^{\circ}$

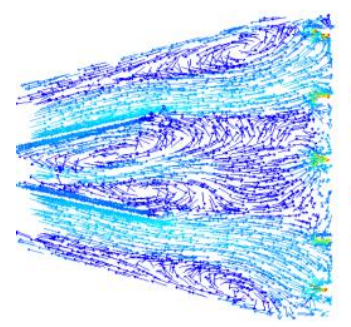

(e) $50030015^{\circ}$

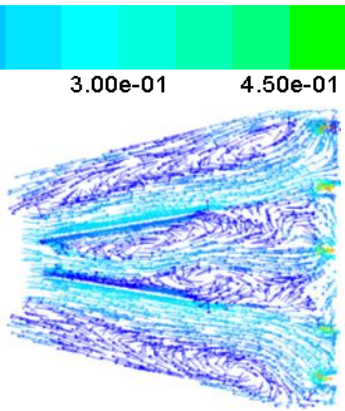

(b) $80030012^{\circ}$

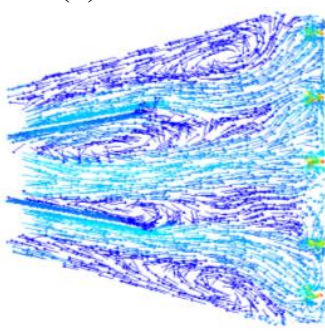

(f) $50050012^{\circ}$

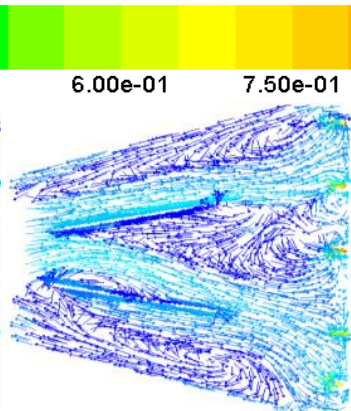

(c) $80040012^{\circ}$

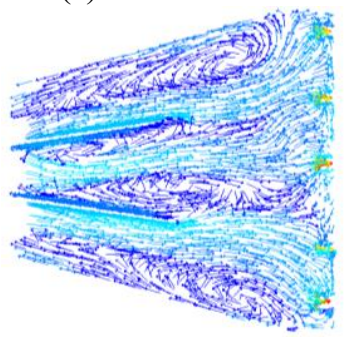

(g) $60040010^{\circ}$

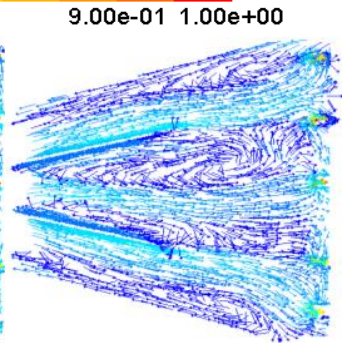

(d) 60040015

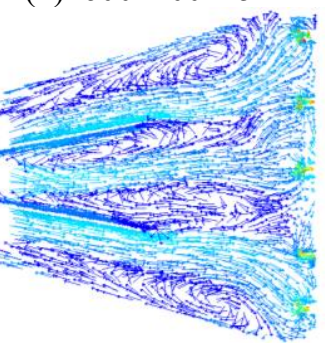

(h) $60040012^{\circ}$

Figure 12. Velocity vector distribution at lower layer in forebay of plan one

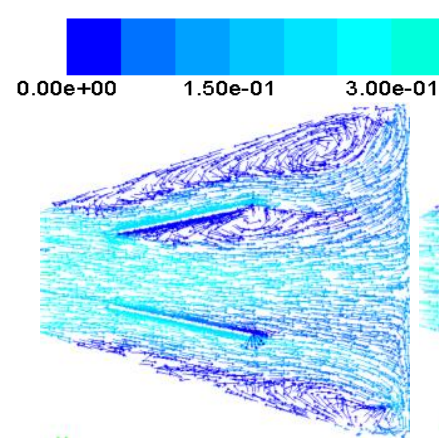

(a) $50050012^{\circ}$

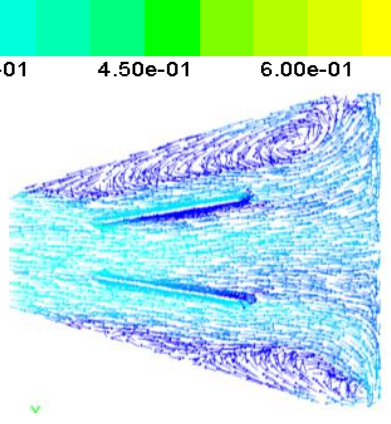

(b) $60040010^{\circ}$

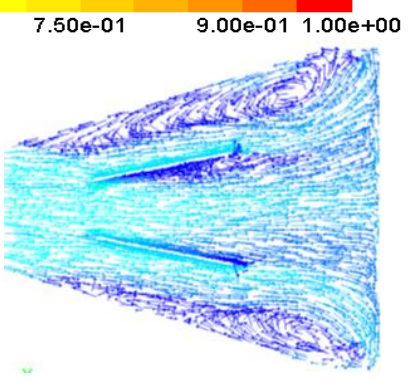

(c) $60040012^{\circ}$

Figure 13. Velocity vector distribution at middle layer in forebay of plan one

\subsection{Plan two}

With the aid of pressure plate, the flow pattern of forebay is mainly improved by guiding and suppressing the water flow. When the mainstream flows through the pressure plate, it is guided and suppressed towards the bottom. As the water velocity increases in the shrank water-carrying section, part of the water diffuses to the two sides, forming a uniform flow towards the inlet tank, while part rolls up to form the turbulent diffusion under the action of the pressure plate. The resulting uniform inlet condition for the pump will substantially boost the pumping efficiency. Moreover, the growing flow velocity is conducive to curbing sedimentation in forebay of pump station. Experiments show that the optimal forebay flow pattern and the best anti-silt effect can be achieved using the $45^{\circ}$ pressure plate [33]. Thus, this plate was adopted to modify the flow pattern in our forebay.

The main control parameters of pressure plate include the underwater penetration of the lower edge of the pressure plate $\mathrm{H}$ and the distance to the forebay inlet L (Figure 14). The optimization of the flow field distribution in the forebay relies on the improvement of the mainstream effect and the effect of horizontal/vertical diffusions. To enhance horizontal diffusion, the underwater penetration of the lower edge of the pressure plate $\mathrm{H}$ should not be too small. Of course, the value of $\mathrm{H}$ should not be too large for the sake of head loss. Furthermore,
$\mathrm{H}$ is negatively correlated with the distance to the forebay inlet $\mathrm{L}$, which has a direct impact on the implementation effect of pressure plate.

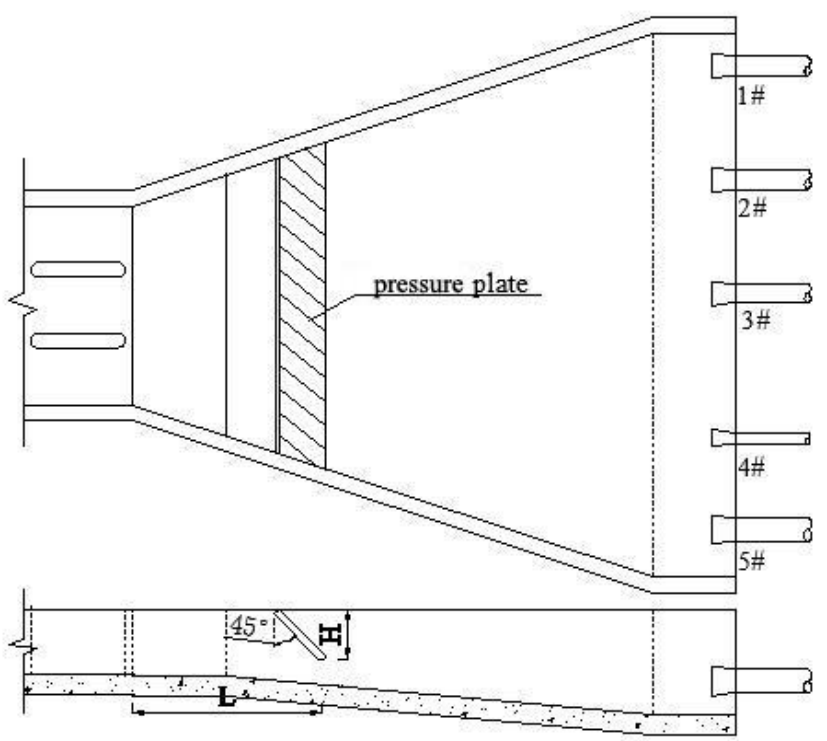

Figure 14. Layout diagram of $45^{\circ}$ pressure plate in SEFI forebay 
The chance of sedimentation is high if $\mathrm{L}$ is too large because the space upstream the pressure plate will be enlarged, the velocity before the plate will slow down, and the silt-carrying capacity will be decrease. If $\mathrm{L}$ is too small, the water will diffuse to the two sides and flow over the pressure plate, the space downstream the pressure plate will be enlarged and the water velocity will gradually decrease; the ensuing uneven flow field distribution will cause sedimentation in the forebay and suppress the pumping efficiency. As a result, the selection of pressure plate parameters controls the modification effect of forebay flow pattern.

Here, 9 combinations of pressure plate parameters are designed (Table 5), the geometric model is established and the grids are divided for each parameter combination. The number of grid units ranged between 1.17 million and 1.173 million. The simulation results of some parameter combinations are shown in Figure 15 (unit: m/s).

Table 5. Parameters of $45^{\circ}$ pressure plate

\begin{tabular}{ccc|ccc|ccc}
\hline NO. & H & L & NO. & H & L & NO. & H & L \\
\hline a & 40 & 600 & d & 60 & 600 & g & 100 & 600 \\
b & 40 & 800 & e & 60 & 800 & h & 100 & 800 \\
c & 40 & 1000 & f & 60 & 1000 & i & 100 & 1000 \\
\hline
\end{tabular}

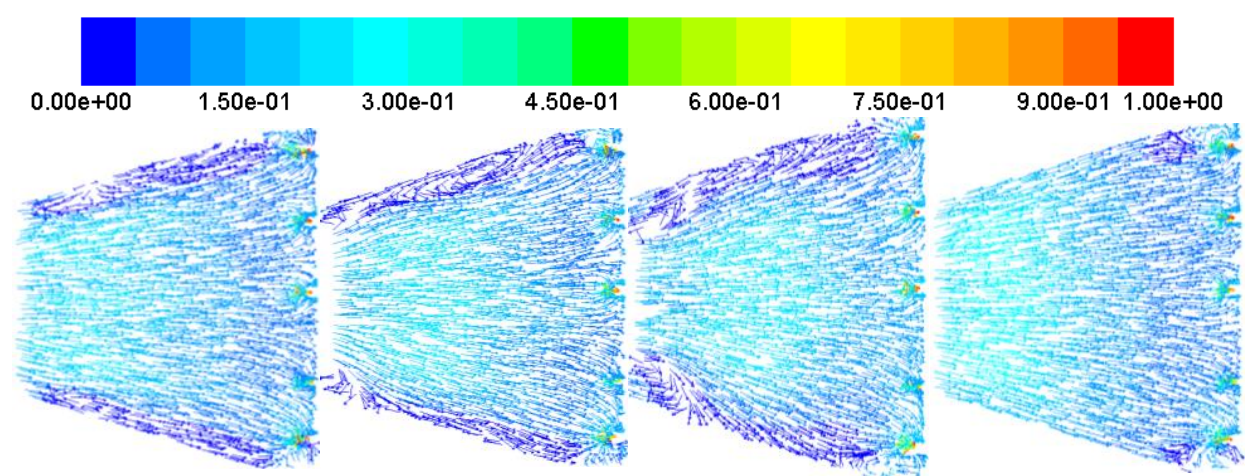

(a)

(b) (d)

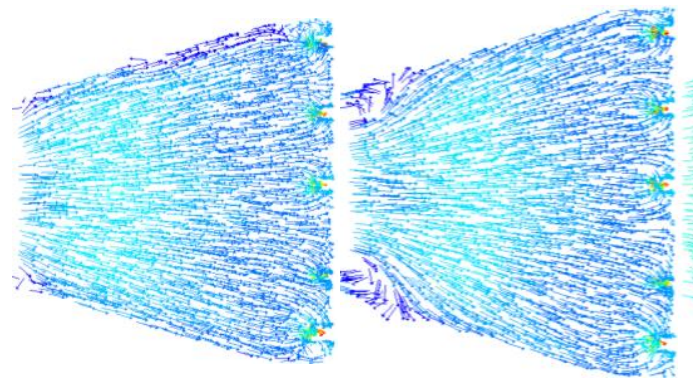

(e) (f)

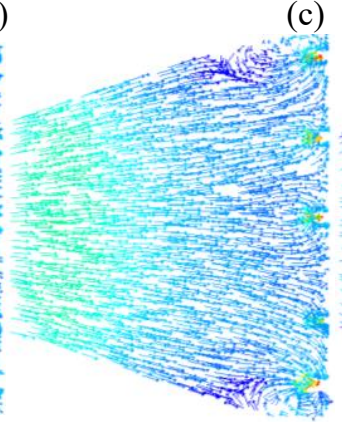

(g)

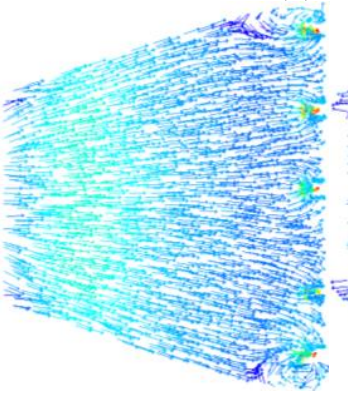

(h)

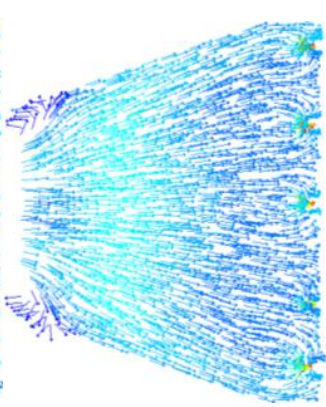

(i)

Figure 15. Velocity vector distribution at lower layer in the forebay of plan two

According to the simulation, the $45^{\circ}$ pressure plate could significantly improve the mainstream effect of forebay, enhance the horizontal and vertical diffusions of water flow and reduce the reflux zone on both side. Thanks to the addition of this plate, the distribution of flow velocity in the upper and lower layers in the forebay became more even. Note that the flow in the upper layer formed a steady state diffusion, which mitigates the sedimentation problem in the forebay and ensures the favourable inlet conditions of the pump. The flow rate of the lower layer increased obviously, and the fast water flow had a scouring effect of the silt at the bottom. Meanwhile, the silt-carrying capacity of the water flow was also increased significantly, making it easier to reduce silt deposition in the forebay.

The modification effect on water flow in the forebay differed with the parameter combinations. Comparing the simulation results, it is clear that the improvement was maximized when the depth $\mathrm{H}$ of the water inlet and the length $\mathrm{L}$ of the inlet of the front pool were respectively $60 \mathrm{~cm}$ and $800 \mathrm{~cm}$ (Figures 15 (d) (f)). When $\mathrm{H}$ was less than $60 \mathrm{~cm}$, the pressure plate had a limited impact on the flow in the forebay, leading to poor diffusion of the mainstream. The belt-shaped low-speed reflux zone appeared on both sides of the forebay, which easily causes severe sedimentation, disordered water flow and poor inlet conditions of the pump (Figures 15(a) (c)). When $\mathrm{H}$ was greater than $60 \mathrm{~cm}$, the effect of the pressure plate on the flow in the forebay was so strong and in-depth as to reduce the thickness of uniform flow velocity area in the lower layer. Sometimes, the thickness was reduced to a level below the suction nozzle of the pump (Figures 15 (g) (i)). In this case, the water intake of the water pump was affected and the pump efficiency was reduced.

In summary, the optimal parameter combination for $45^{\circ}$ pressure plate parameters was $\mathrm{H}=60 \mathrm{~cm}$ and $\mathrm{L}=800 \mathrm{~cm}$.

\subsection{Onsite tests}

From January 2015 to May 2015, the \#3 Pump Station of West Trunk Line (Phase I) carried out onsite tests by plan one. The results show that many silts were still deposited on both sides of the side wall and the diversion pier. From February to June, 2016, the pump station modified its forebay by plan two. This time, the silts were basically cleared from the two sides of the forebay, and the pump efficiency was significantly improved. Table 6 records the silt deposition degree and related performance parameters of pump station before and after the modification. 
Table 6. Results before and after the modification

\begin{tabular}{|c|c|c|c|c|c|c|c|c|c|c|c|}
\hline & \multirow{2}{*}{$\begin{array}{l}\text { Silting } \\
\text { location }\end{array}$} & \multirow{2}{*}{$\begin{array}{c}\text { Top } \\
\text { sedimentation } \\
\text { thickness }(\mathrm{m})\end{array}$} & \multirow{2}{*}{$\begin{array}{l}\text { Flow } \\
\left(\mathrm{m}^{3} / \mathrm{s}\right)\end{array}$} & \multirow{2}{*}{$\begin{array}{c}\text { Total } \\
\text { head } \\
(\mathrm{m})\end{array}$} & \multicolumn{2}{|c|}{ Power (kW) } & \multirow[b]{2}{*}{ Pipelineloss(m) } & \multicolumn{3}{|c|}{ Efficiency $(\%)$} & \multirow[b]{2}{*}{ Device } \\
\hline & & & & & $\begin{array}{c}\text { Input } \\
\text { power }\end{array}$ & $\begin{array}{l}\text { Shaft } \\
\text { power }\end{array}$ & & Motor & $\begin{array}{l}\text { Water } \\
\text { pump }\end{array}$ & Pipeline & \\
\hline $\begin{array}{c}\text { Before } \\
\text { transformation }\end{array}$ & $\begin{array}{l}\text { Both sides of } \\
\text { forebay }\end{array}$ & 2.6 & 4.43 & 28.29 & 186 & 163.68 & 0.56 & 85.98 & 68.96 & 86.43 & 51.43 \\
\hline \multirow{2}{*}{$\begin{array}{l}\text { Diversion pier } \\
\text { transformation }\end{array}$} & $\begin{array}{l}\text { Both sides of } \\
\text { forebay }\end{array}$ & 1.9 & \multirow{2}{*}{4.48} & \multirow{2}{*}{27.96} & \multirow{2}{*}{173} & \multirow{2}{*}{152.24} & \multirow{2}{*}{0.60} & \multirow{2}{*}{85.98} & \multirow{2}{*}{70.13} & \multirow{2}{*}{85.30} & 51.43 \\
\hline & $\begin{array}{l}\text { Both sides of } \\
\text { diversion pier }\end{array}$ & 0.9 & & & & & & & & & \\
\hline $\begin{array}{l}\text { Depressed plate } \\
\text { transformation }\end{array}$ & $\begin{array}{l}\text { Both sides of } \\
\text { forebay }\end{array}$ & 0.4 & 4.56 & 27.97 & 170 & 149.60 & 0.59 & 85.98 & 74.56 & 85.31 & 54.69 \\
\hline
\end{tabular}

The onsite tests reveal that the flow pattern in the forebay was greatly improved after the application of $45^{\circ}$ pressure plate, as evidenced by the obvious increase in the flow and the elimination of silts. Since the pump efficiency equals (flow $\times$ head) / shaft power, it can be seen from Table 6 that the efficiency of the pump increased by $5.71 \%$ and $8.68 \%$ respectively after the modification by trapezoid diversion pier and $45^{\circ}$ pressure plate.

\subsection{Discussion}

In this paper, trapezoid diversion pier and $45^{\circ}$ pressure plate was used to simulate the flow pattern of the forebay of pump station in the study area. The trapezoid diversion pier has a certain shunting and guiding effect on the water flow. The rational setting of the pier can effectively improve the flow field distribution in the forebay. However, the pier only distributes the water flow in the forebay, failing to get a relatively good flow pattern. The effect of the diversion pier varies with the parameter combinations. What is worse, the application of the pier requires numerous design parameters and complex optimization, despite the relatively poor results. By contrast, the $45^{\circ}$ pressure plate has a much better improvement effect than the trapezoid diversion pier. The addition of the plate can reduce silt deposition with a simple parameter design, laying the basis for anti-silt optimization of the similar SEFI forebays in the irrigation district.

Of course, there is still much room for improvement in the following aspects: the flow pattern modification is affected by the location, tilt angle and suspension height of the pressure plate; the effects of different water levels and unit combinations on forebay water regime and sedimentation remain unclear; the combination of different modification measures is yet to be discussed.

\section{CONCLUSIONS}

Targeting the \#3 pump station of West Trunk Line (Phase I), Gansu Jingtaichuan Irrigation District, this paper numerically simulates the flow pattern in SEFI forebay on FLUENT. The simulation results show that the sedimentation occurred mainly in the reflux zone in the middle and downstream on both sides of the forebay; the sedimentation problem was very prominent in the forebay as the maximum sedimentation range covered $1 / 2$ of the entire volume. The heavy presence of the silts narrows the water carrying channel, worsens the pump intake conditions, and severely affects the performance of the pump station. The simulated results agree well with the site investigation. This means the numerical simulation can provide a reliable reference for the optimization and reconstruction of the forebay.
The trapezoid diversion pier has a certain distribution and guiding effect on the water flow of the forebay. However, the application of the pier failed to significantly improve the mainstream effect or change the range of reflux zone and flow velocity. On the contrary, the addition of the $45^{\circ}$ pressure plate could significantly improve the mainstream effect of SEFI forebay, increase the forebay flow velocity at the bottom, and enhance the horizontal diffusions of water flow. In this way, the sedimentation of the forebay can be mitigated and the inlet condition of the pump can be improved. The best modification effect appeared at $\mathrm{H}=60 \mathrm{~cm}$ and $\mathrm{L}=800 \mathrm{~cm}$ of the $45^{\circ}$ pressure plate.

\section{ACKNOWLEDGMENT}

This work was supported by the National Natural Science Foundation of China [grant numbers 51579102, 31360204], the Support Plan of Innovative Talents of Science and Technology of Henan Province [grant number 174200510020], the Support Plan of Innovative Team of Science and Technology of University of Henan Province [grant number 19IRTSTHN030], the Special Project of Science and Technology of Water Conservancy of Ningxia Hui Autonomous Region [grant number TYZB-ZFCG-2017-31] and Doctoral Graduate Innovation Fund of North China University of Water Resources and Electric Power.

\section{REFERENCES}

[1] Xu CD. (2003). Applied research on construction supervision system of high-lift pumping cascade irrigation project. Northwest A\&F University, Xianyang.

[2] Mi ZH, Zhou DQ, Mao YT. (2015). Three-dimensional CFD simulation of inlet structure flow in pump station based on Eulerian solid- liquid two-phase flow model. Journal of Drainage and Irrigation Machinery Engineering 15(6): 494-498. https://doi.org/10.1088/1755-1315/15/6/062027

[3] Fletcher BP, Grace JL. (1977). Source: United states waterways experiment station. Technical Report, Vicksburg.

[4] Shafai-Bajestan M, Behzadi-Poor A, Abt SR. (1998). Source: International water resources engineering conference-proceedings: 1553-1558.

[5] Constantinescu GS, Patel VC. (2000). Role of turbulence model in prediction of pump-bay vortices. Journal of Hydraulic Engineering 126(5): 387-391. http://dx.doi.org/10.1061/(ASCE)07339429(2000)126:5(387)

[6] Liu XY, Gao CC, Shi LW, Liu W. (2010). Numerical 
simulation for fluid meliorating in both forebay and suction bay of pump stations. Journal of Drainage and Irrigation Machinery Engineering 28(3): 242-246.

[7] Han JQ, Li YW, Gao DS, Cao K, Huang LW. (2012). 3D Numerical simulation and optimum design of circulating water pump flow channel in thermal plant. Yellow River.

[8] Nakato T. (2004). Application of suction scoops to improve pump-approach flow distributions in threepump intake bays. World Water and Environmental Resources Congress, pp. 1-10.

[9] Zhou DQ, Mi ZH, Mao YT. (2013). 3D Numerical simulation of inlet structure flow in pump station based on eulerian solid-liquid two-phase flow model. Transactions of the Chinese Society of Agricultural Machinery 44: 48-52.

[10] Yu YH, Cheng B. (2012). CFD simulation and optimization on inflow pattern of diversion and intake pump stations with side-inlets Water Resources \& Hydropower Engineering 43: 72-75.

[11] Cheng B, Yu YH. (2012). CFD simulation and optimization for lateral diversion and intake pump stations. Procedia Engineering 28: 122-127.

[12] Hou CS. (2012). Three-dimensional numerical analysis of flow pattern in pressure forebay of hydropower station. Procedia Engineering 28: 128-135.

[13] Cong GH, Wang FJ. (2008). Applicability of turbulence models in numerical simulation of vortex flow in pump sump. Transactions of the Chinese Society of Agricultural Engineering 24: 31-35.

[14] Goudarzizadeh R, Hedayat N, Jahromi SHM. (2010). Three-dimensional simulation of flow pattern at the lateral intake in straight path, using finite-volume method. World Academy of Science Engineering \& Technology (71): 656.

[15] Kim HR, Kim SK, Kim MS, Park SH, Min JK, Ha MY. (2016). Numerical study of fluid flow and convective heat transfer characteristics in a twisted elliptic tube. Journal of Mechanical Science and Technology 30(2): 719-731.

[16] Luo C, Qian J, Liu C, Chen F, Xu J, Zhou QL. (2015). Numerical simulation and test verification on diversion pier rectifying flow in forebay of pump station for asymmetric combined sluice-pump station project. Transactions of the Chinese Society of Agricultural Engineering 26(1): 71-78.

[17] Ji BB, Chen JP. (2012). The example of ANSYS ICEM CFD meshing technology. China Water Power Press, Beijing.

[18] Cheng L, Liu C, Zhou JR, Tang FP. (2001). Numerical simulation of sill flows in the forebay of pump station. Journal of Hohai University: Natural Sciences 29: 42-45.

[19] Xu CD, Yang K, Zhou LB, Song YZ, He SM. (2011). Numerical simulation on geometric form of pump sump in the Yellow River Pump Station. Journal of Gansu Sciences 23: 150-154.

[20] Liu C, Cheng L, Tang FP. (2001). Numerical simulation of three-dimensional turbulent flow for pumping forebay. Journal of North China University of Water
Resources and Electric Power (Natural Science Edition) 36-40.

[21] Gao CC, Huang JW, Wang WS. (2007). Numerical simulation of flow field in sediment pump station forebay. China Water Transport 7: 81-83.

[22] Marovic B, Kolak D. (2012). Combination of CFD dimensions: Industry wide first universal-1D-/3Dcomputational fluid dynamics simulation software. Mechatronik 120: 34-35.

[23] Zeng H. (2014). Design optimization of pump station forebay based on the CFD numerical simulation. Hunan University, Changsha, C.S.

[24] Chen S. (2018). Numerical simulation of split-hopkinson pressure bar test on high-density polyethylene. Chemical Engineering Transactions 66: 271-276. https://doi.org/10.3303/CET1866046

[25] Thanh TT, Kim DH. (2016). A CFD study into the influence of unsteady aerodynamic interference on wind turbine surge motion. Renewable Energy 90: 204-228. https://doi.org/10.1016/j.renene.2015.12.013

[26] Tang XL, Wang WC, Wang FJ, Li YJ. (2011). Numerical simulation of slit-laden flows in pump station forebay. Journal of Drainage and Irrigation Machinery Engineering 29(5): 411-417.

[27] Zheng X. (2018). Numerical simulation of aseismatic reinforced concrete frame structure with fiber reinforced plastics. Chemical Engineering Transactions 66: 11411146. https://doi.org/10.3303/CET1866191

[28] Xu CD, Cui XY, Wang XZ. (2010). Research on the reasons of the sediment deposition and the measures of anti-sedimentation in the side direction inflow forebay of pump station. New Technology \& New Process 1: 5-8.

[29] Yu H. (2018). Numerical simulation of European option payoff based on stochastic differential delay equations. Mathematical Modelling of Engineering Problems 5(2): 102-107. Https://doi.org/10.18280/mmep.050207

[30] Chen SS, Yan HQ, Zhou ZF, He ZG, Wang L. (2014). Three-dimensional turbulent numerical simulation and model test of front-shaft tubular inlet conduit of pump station. Transactions of the Chinese Society of Agricultural Engineering 30: 63-71.

[31] Rafiee A, Cummins S, Rudman M, Thiagarajan K. (2012). Comparative study on the accuracy and stability of SPH schemes in simulating energetic free-surface flows. European Journal of Mechanics B-Fluids 36: 1-16.

[32] Zi D, Wang FJ, Yao ZF, Hou YK, Xiao RF, He CL, Yang EB. (2015). Effects analysis on rectifying intake flow field for large scale pump station with combined diversion piers. Transactions of the Chinese Society of Agricultural Engineering 31: 71-77.

[33] Bi SD, Liu MQ, Xu MS, Long XP. (2014). Analysis on the flow field of inlet structure of Xingshipo pump station by CFD method. International Symposium on Fluid Machinery and Fluid Engineering. IET 1-5.

[34] The Ministry of Water Resources of the People's Republic of China. (2011). Design code for pump station: GB 50265-2010. China Planning Press, Beijing. 